\title{
Placental thickness: a sonographic parameter for estimation of gestational age
}

\author{
Meenambiga Balakrishnan*, Thendral Virudachalam
}

Department of Obstetrics and Gynecology, Thanjavur Medical College, Thanjavur, Tamilnadu, India

Received: 04 October 2016

Accepted: 02 November 2016

\section{*Correspondence:}

Dr. Meenambiga Balakrishnan,

E-mail: m.ambiga@ rediffmail.com

Copyright: $\odot$ the author(s), publisher and licensee Medip Academy. This is an open-access article distributed under the terms of the Creative Commons Attribution Non-Commercial License, which permits unrestricted non-commercial use, distribution, and reproduction in any medium, provided the original work is properly cited.

\section{ABSTRACT}

Background: The aim and objective of the study was to evaluate the placental thickness as a sonographic parameter for estimation of gestational age, to find out if a correlation exists between the placental thickness and maternal age, parity and menstrual age, to identify the differences in ultrasonographic placental thickness with advancing gestational age based on implantation site.

Methods: The present study was conducted in the department of obstetrics and Gynecology, Thanjavur Medical College. Patients with known LMP, >11 Weeks GA, singleton pregnancies with no fetal anomalies and with no associated medical or obstetrical complications were included. With 2D USG machine, Along with fetal biometry, placental thickness was measured at its midposition or at the level of cord insertion. Patients were followed until delivery.

Results: Out of 2100 women, 120 didn't turn up. Hence 1980 patients were included. Using Pearson correlation, correlation between placental thickness and maternal age, gestational age were analysed. There is statistically significant correlation between GA and placental thickness $(\mathrm{p}<0.01)$. The value of mean placental thickness increases with advancing gestational age almost matching from 20th to 35th week. There is no statistically significant difference between placental thickness with advancing gestational age based on implantation site $(\mathrm{p}=0.16)$.

Conclusions: The measurement of placental thickness is an important parameter for estimation of fetal age, it is helpful in cases where exact duration of pregnancy is not known (between 20 and 35 weeks) where the placental thickness almost matches with gestational age. It can also be used as a predictor of LBW, IUGR, hydrops fetalis.

Keywords: Placental thickness, Ultrasonographic gestational age

\section{INTRODUCTION}

The role of ultrasonography in obstetric management has been immense. This is evolved over time from the basic 2-D imaging to Doppler imaging to assess the fetal and maternal circulation and to 3-D imaging of fetal anatomy. ${ }^{1}$ Obstetrical ultrasound has proven invaluable in a variety of ways, in particular being more accurate for pregnancy dating and detection of fetal anomalies.

Several investigations have demonstrated that an estimated gestational age determined sonographically is more accurate that one based on the last menstrual period. Accurate dating also alters the method of pregnancy termination. Various formulas and nomograms allow accurate assessment of gestational age and describe normal growth of fetus. ${ }^{2}$ Estimates are typically most accurate when multiple parameters are used and when nomograms have been derived from foetuses of the same ethnic or racial background, living at a similar altitude.

The placenta is a fetal organ which provides the physiologic link between a pregnant woman and the fetus. The placenta develops from the chorionic villi at 
the implantation site at about the fifth week of gestation and by the ninth to tenth week, the diffuse granular echo texture of the placenta is clearly apparent at sonography. ${ }^{3}$ Placental thickness appears to be a promising parameter for estimation of gestational age of the fetus because of increase in placental thickness with gestational age. Studies Mital et al. ${ }^{5}$ and Jain et al. ${ }^{6}$ have reported the use of placental thickness as an indicator of gestational age.

The present study was undertaken in our institution to study the correlation of placental thickness, measured at the level of the umbilical cord insertion, with the ultrasonographic gestational age in normal pregnancies in the second and third trimester (Figure 1).

\section{METHODS}

The present study entitled 'Placental Thickness-A Sonographic Parameter for Estimation of Gestational Age' was conducted in the Department of Obstetrics and Gynecology, Thanjavur Medical College, Tamilnadu, India.

\section{Selection criteria}

$\checkmark \quad$ Patients with known dates of last menstrual period

$\checkmark$ More than 11 weeks GA

$\checkmark$ Singleton pregnancies with no fetal or congenital anomalies

$\checkmark \quad$ No medical or obstetrical complications

\section{Examination method}

1. A thorough history regarding medical illness and obstetric history was taken for each patient

2. Symphysio - fundal height was measured after emptying the bladder. Fundal height by palpation and gestational age was clinically assessed.

3. Consent for doing ultrasound and their co-operation for the study was taken.

4. Routine ultrasound scanning was done in all cases, in all trimester, transabdominally with a real time ultrasound.

Machine used for study was Sonoray 2D ultrasound unit with a $3.5 \mathrm{MHz}$ convex transducer. The patients were scanned with optimally filled bladder in supine position.

After an initial survey with ultrasound transducer in each patient, all measurements needed for fetal biometry were taken:

1. CRL up to 11 weeks

2. Femur length

3. Biparietal diameter

4. Abdominal circumference
The placental thickness was measured at its midposition or at the level of cord insertion. ${ }^{2}$ Multiple longitudinal and transverse scans were needed to demonstrate placenta completely. ${ }^{2,4}$ Uterine contractions can mimic the placenta so repeat the scan after 5 minutes. The patients were followed until delivery.

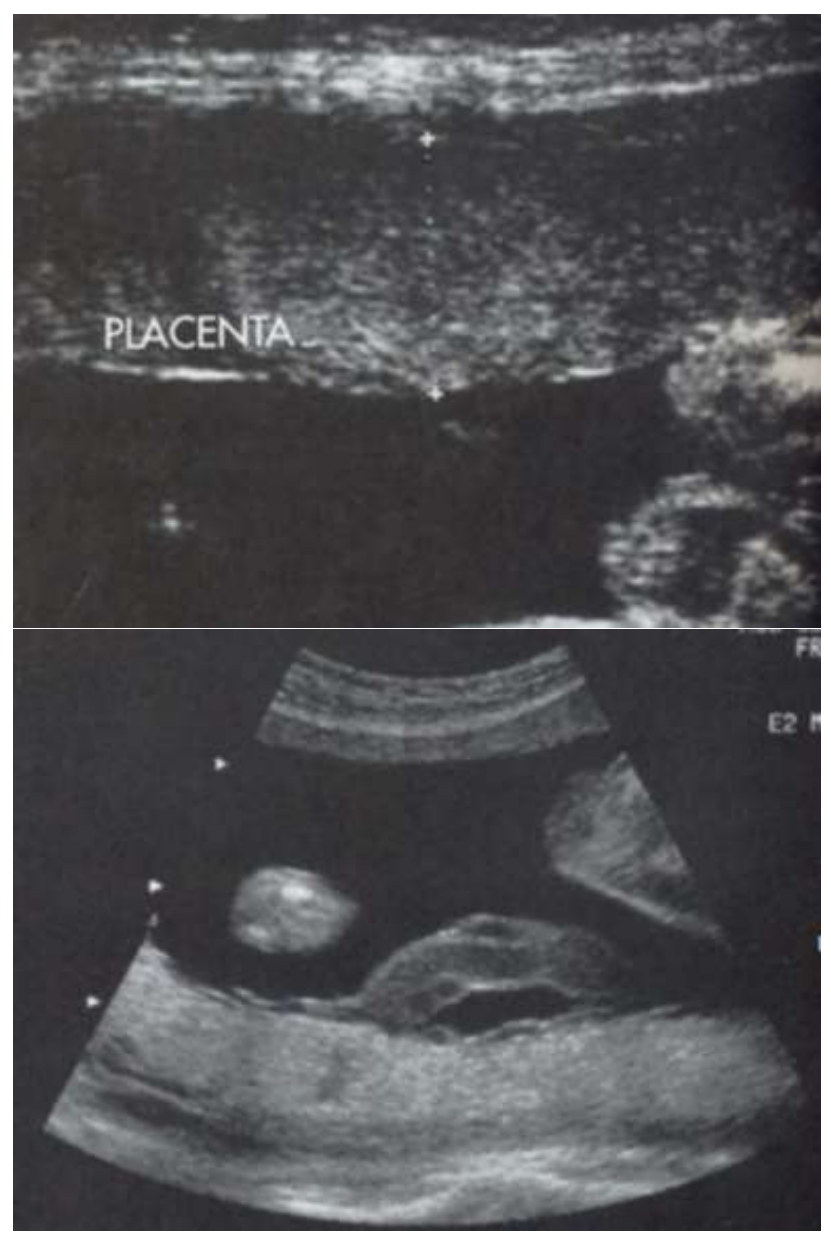

Figure 1: Thickness of placenta and umbilical cord insertion.

\section{RESULTS}

Table 1: Maternal age.

\begin{tabular}{|lll|}
\hline Maternal age & No. of cases & $\%$ \\
\hline$\leq 19$ & 80 & 4.04 \\
\hline $20-24$ & 710 & 35.86 \\
\hline $25-29$ & 930 & 46.97 \\
\hline $30-34$ & 250 & 12.62 \\
\hline$\geq 35$ & 10 & 0.51 \\
\hline
\end{tabular}

In our study 2100 uncomplicated antenatal cases of more than 11 weeks gestation were included. Along with other fetal biometry, placental thickness was measured and the labor outcomes of those women were followed. 
Table 2: Parity.

\begin{tabular}{|lll|}
\hline Parity & No. of cases & $\%$ \\
\hline Primi & 950 & 47.97 \\
\hline Multi & 1030 & 52.03 \\
\hline
\end{tabular}

Table 3: Placental location.

\begin{tabular}{|lll|}
\hline Location & No. of cases & $\%$ \\
\hline Anterior & 1000 & 50.5 \\
\hline Posterior & 680 & 34.4 \\
\hline Lateral & 40 & 2.0 \\
\hline Fundal & 230 & 11.6 \\
\hline Low lying & 30 & 1.5 \\
\hline
\end{tabular}

Table 4: Placental thickness vs gestational age.

\begin{tabular}{|c|c|c|c|}
\hline GA weeks & No & Mean & SD \\
\hline 11 & 10 & 1.40 & - \\
\hline 12 & 10 & 1.40 & - \\
\hline 13 & 110 & 1.40 & 0.05 \\
\hline 14 & 10 & 1.50 & - \\
\hline 15 & - & - & - \\
\hline 16 & 20 & 1.70 & - \\
\hline 17 & - & - & - \\
\hline 18 & 10 & 1.80 & - \\
\hline 19 & 80 & 1.92 & 0.07 \\
\hline 20 & 150 & 2.00 & 0.05 \\
\hline 21 & 260 & 2.06 & 0.06 \\
\hline 22 & 80 & 2.21 & 0.11 \\
\hline 23 & 70 & 2.33 & 0.049 \\
\hline 24 & 40 & 2.40 & 0.00 \\
\hline 25 & 40 & 2.50 & 0.00 \\
\hline 26 & 80 & 2.55 & 0.00 \\
\hline 27 & - & - & - \\
\hline 28 & 70 & 2.77 & 0.76 \\
\hline 29 & - & - & - \\
\hline 30 & 50 & 2.96 & 0.05 \\
\hline 31 & 90 & 3.07 & 0.87 \\
\hline 32 & 120 & 3.23 & 0.05 \\
\hline 33 & 130 & 3.29 & 0.11 \\
\hline 34 & 50 & 3.40 & 0.09 \\
\hline 35 & 60 & 3.52 & 0.04 \\
\hline 36 & 160 & 3.56 & 0.17 \\
\hline 37 & 110 & 3.65 & 0.14 \\
\hline 38 & 120 & 3.71 & 0.16 \\
\hline 39 & 30 & 3.90 & 0.17 \\
\hline 40 & 20 & 3.85 & 0.07 \\
\hline
\end{tabular}

Out of 2100 women, 120 didn't turn up for their delivery to our hospital. Hence only 1980 patients who delivered in our hospital were included. The results were analysed with respect to the maternal age, parity, placental thickness, and placental location, mode of delivery, birth weight, and gestational age at birth. The mean values of placental thickness along with the respective standard deviation were calculated for different gestational age from 11 weeks to 40 weeks.

Using Pearson correlation, correlation between Placental thickness and Gestational Age and Maternal age were analysed.

Using chi square test correlation between placental thicknesses with advancing gestation and implantation site was analysed.

Table 5: Birth weight.

\begin{tabular}{|lll|}
\hline Weight & No. of cases & $\%$ \\
\hline$<1.99$ & 0 & \\
\hline $2-2.49$ & 60 & 3.1 \\
\hline $2.5-2.99$ & 940 & 47.4 \\
\hline $3-3.49$ & 830 & 41.9 \\
\hline$>3.5$ & 150 & 7.6 \\
\hline
\end{tabular}

Table 6: Various variables and its significance.

\begin{tabular}{|lll|}
\hline Variable & $\begin{array}{l}\text { Tests of significance } \\
\text { GA by LMP }\end{array}$ & $\begin{array}{l}\text { Pearson Correlation } \\
\text { (r2=0.99) }\end{array}$ \\
\hline Maternal age & $\begin{array}{l}\text { Pearson Correlation(r2=- } \\
\text { 0.04) }\end{array}$ & 0.54 \\
\hline Parity & t- test & 0.40 \\
\hline $\begin{array}{l}\text { Placental } \\
\text { location }\end{array}$ & Chi square & 0.16 \\
\hline
\end{tabular}

\section{DISCUSSION}

Accurate determination of gestational age has become important for deciding the appropriate time for termination of the pregnancy as well as to monitor the fetal growth during the entire period of pregnancy. In addition to the routine fetal biometry parameters, various studies were done trying to deduce a relationship between the placental thickness and gestational age and the estimated fetal weight.

A fairly linear increase in mean placental thickness with gestational age was observed in correlation analysis studies conducted to determine the relationship between placental thickness and gestational age. The value of the mean placental thickness increased with advancing gestational age, almost matching from the $22^{\text {nd }}$ to the $35^{\text {th }}$ week.

In our study we analysed 1980 uncomplicated pregnancies of more than 11 weeks gestation till term. All of them had normal fetal outcome. Placental thickness was measured at the insertion of cord or at its midposition.

The mean values of placental thickness along with respective standard deviation were calculated for different gestational ages from $11^{\text {th }}$ week to $40^{\text {th }}$ week. It 
was observed that the placental thickness gradually increased from $1.4 \mathrm{cms}$ at 11 weeks of gestation to 3.8 $\mathrm{cms}$ at 40 weeks of gestation.

In our study up to 19 weeks of gestation the mean placental thickness was slightly higher than the gestational age by $0.1-0.4 \mathrm{cms}$. From 20 weeks to 35 weeks of gestation the placental thickness almost matched the gestational age in weeks. There after the placental thickness was lower by 0.1 to $0.2 \mathrm{cms}$.

The present study assessed the relationship between the gestational in weeks and placental thickness in cms by ultrasound. The value of mean placental thickness increases with advancing gestational age almost matching from $20^{\text {th }}$ week to $35^{\text {th }}$ week.

Our study results are consistent with observations made by Mittal et al, Jain A who reported the mean placental thickness increased with advancing gestation and almost matches from 22 to 35 weeks. ${ }^{5,6}$

In our study there is statistically significant correlation between placental thickness and gestational age (r2=0.99), $(\mathrm{P}<0.01)$.

According to regression analysis, for every one unit (week) increase in gestational age the placental thickness increases by 5.25 units (i.e. $0.5 \mathrm{cms}$ ).

There is no statistically significant correlation between the placental thickness and maternal age ( $\mathrm{r} 2=-0.044)$, $(\mathrm{P}<0.54)$, parity $(\mathrm{P}=0.40)$ which is consistent with findings of Elchalal et al and Durnwald et al study. ${ }^{11,12}$

In our study there is no significant difference in placental thickness with advancing gestation based on implantation site $(\mathrm{P}=0.16)$ unlike Durnwald et al study in which placental thickness of posterior and fundal placenta in $3^{\text {rd }}$ trimester was greater than anterior placenta. ${ }^{7}$

Habib FA framed a warning limit of placental thickness of $2 \mathrm{cms}$ at 36 weeks gestation as a predictor of LBW infants and subsequent IUGR. ${ }^{8,9}$ In our study none of the cases at 36 weeks had placental thickness of less than $2 \mathrm{cms}$.Hence it is unable to show whether placental thickness can be used as a predictor of LBW, IUGR.

Elchalal et al analysed sonographically thick placenta (> $4 \mathrm{cms}$ or $>90^{\text {th }}$ percentile) is associated with increased perinatal mortality and morbidity like fetal anomalies, SGA, LGA infants at term. In our study none of the cases had placental thickness of more than $4 \mathrm{cms}$.

Since there is statistically significant correlation between placental thickness and gestational age, placental thickness can be used as a reliable parameter in late $2^{\text {nd }}$ and $3^{\text {rd }}$ trimester for calculating gestational age. It is also useful in certain situations like: $\checkmark$ Occipito posterior position

$\checkmark$ Dolicocephaly

$\checkmark$ Brachycephaly

$\checkmark$ Breech

$\checkmark$ Deeply engaged head, Where BPD is less reliable.

\section{Uses of placental thickness}

$\checkmark \quad$ To determine gestational age in late $2^{\text {nd }}, 3^{\text {rd }}$ trimester when exact duration of pregnancy is not known

$\checkmark$ As a predictor for LBW

$\checkmark$ Prognostic value in identifying subsequent occurrence of IUGR.

$\checkmark \quad$ Placental thickness at mid pregnancy (18 -21 weeks) as a predictor of $\mathrm{Hb}$ Barts ${ }^{10}$ disease there by reducing the number of invasive diagnostic procedures.

Determination of Gestational age is very essential, so that iatrogenic prematurity can be prevented, which is very essential in the management of all pregnancies in particular with regards to methods if termination (MTP).

Elective planned induction of labor management of high risk pregnancies where in all these conditions, correct assessment of fetal age is mandatory.

So in some exceptional cases, when normality of any one of the parameters like BPD, AC or FL is in doubt, gestational age can be assigned by placental thickness.

\section{CONCLUSION}

The age, parity, placental location shows no significant bearing in the assessment of placental thickness and its correlation to gestational age. In our study, placental thickness increases with advancing gestation almost matching from 20 to 35 weeks.

The present study has shown a significant correlation between the placental thickness and gestational age particularly in late 2nd and 3rd trimester.

To conclude, one can say the measurement of placental thickness is an important parameter for estimation of fetal age. It is helpful in cases where the exact duration of pregnancy is not known (between 20 and 35 weeks) where the placental thickness almost matches with gestational age. Besides in determining gestational age placental thickness can be used as a predictor of LBW, IUGR, Hb Bart's disease (Hydrops fetalis).

\section{ACKNOWLEDGEMENTS}

The Authors acknowledgement the valuable contribution and support by all the faculties of Department of Obstetrics and Gynaecology, Thanjavur Medical College in this study. 
Funding: No funding sources

Conflict of interest: None declared

Ethical approval: The study was approved by the Institutional Ethics Committee

\section{REFERENCES}

1. Cunnigham FG, Leveno KJ, Bloom SL, et al, In ultrasonography and Doppler, Williams obstetrics, 22nd ed., New York, McGraw Hill; 2005; p. 389-90.

2. Rumack CM, Wilson SK, Charboneau JN, et al, In fetal measurements-normal and abnormal fetal growth, diagnostic ultrasound- obstetric and fetal sonography, 3rd ed. St Louis; Elsevier Mosby: 2005; p. $1499-500$.

3. Sandra L. Text Book of Diagnostic Ultrasound, 6th edition. Vol 2. pp. 969-975, 1138-1156.

4. Palmer PES. Manual of Diagnostic Ultrasound, Millennium edition, WHO, Geneva pp. 273-276.

5. Mittal P, Hooja K. Placental Thickness - A Sonographic Parameter for Gestatational age Estimation. Indian J Radiol Imag. 2002;12(4):553-4.
6. Jain A. Placental Thickness - A Sonographic indicator of Gestational age. J Obs Gyn of India. 2001;51(3):48-9.

7. Ultrasonographic Placental thickness for Gestational age estimation: Am J of Obs Gyn. 1998;178(1s):167.

8. Habib FA. Prediction of LBW infants from Placental Diameter and Thickness. Ann Saudi Med. 2002;22(5-6):312-4.

9. Tongsong T, Wanapirak C. Placental Thickness at midpregnancy as a predictor for Hb Barts Disease. Prenatal diagnosis. 1999;19(11):1027-30.

10. Ghosh A, Tang MH, Lam et al: Ultrasonic Placental Thickness to detect Pregnancies affected by Alpha Thalassemia. Lancet. 1994;344:988-9.

11. Elchalal U, Levi Y. Sonographically thick Placenta a marker for perinatal risk. Placenta. 2000;21:268-72.

12. Durnwald C, Mercer B. Ultrasonic estimation of placental thickness with advancing gestational age. Am J Obs Gyn. 2004;191(6):178.

Cite this article as: Meenambiga B, Thendral V. Placental thickness: a sonographic parameter for estimation of gestational age. Int J Reprod Contracept Obstet Gynecol 2016;5:4377-81. 